\title{
Introduction to Journal of Thoracic Disease new column of advance in bronchoscopy for peripheral pulmonary diseases
}

The diagnosis of peripheral pulmonary lesions (PPLs) has always been a challenging clinical problem (1-3). Bronchoscopy has been widely used for the diagnosis of PPLs. With the continuous improvement of instruments and development of technologies, especially with the advent of guided bronchoscopy, the diagnostic yield of bronchoscopy has been gradually enhanced (4). Guided bronchoscopy refers to bronchoscopy used for the diagnosis and treatment of PPLs, which is different from conventional bronchoscopy used for the diagnosis and treatment of visible lesions in the lumen. It includes technologies such as thin/ultrathin bronchoscopy, endobronchial ultrasound, guide sheath, and navigation bronchoscopy. With advancements in technology, guided bronchoscopy is changing with each passing day. Thus, we have launched a special column on the progress of guided bronchoscopy.

This column contains two reviews and three original articles, which systematically illustrate the application value of guided bronchoscopy in PPLs from the perspectives of development of ultrathin bronchoscopy and navigation bronchoscopy, as well as convex probe endobronchial ultrasound (CP-EBUS) and radio probe (RP)-EBUS sonographic features, virtual bronchoscopy navigation (VBN), and RP-EBUS-guided transbronchial lung cryobiopsy (TBLC).

Standard bronchoscopy with an external diameter of $5 \mathrm{~mm}$ is not suitable for PPLs located at distal branches and smaller bronchi. The ultrathin bronchoscopy, with external diameter no more than $3.5 \mathrm{~mm}$, shows significant diagnostic advantages in this situation. The review on ultrathin bronchoscopy discusses the diagnostic value of various types of ultrathin bronchoscopies in PPLs, from the perspectives of technology application, diagnostic yield, clinical studies, safety, and limitations. Navigation technologies can help bronchoscopists precisely reach the site of PPLs for biopsy. The most commonly used navigation technologies currently include VBN and electromagnetic navigational bronchoscopy (ENB). Augmented fluoroscopy, cone beam computed tomography (CT), and robotic assisted bronchoscopy are newly developed navigation technologies. The review related to navigation bronchoscopy provides a comprehensive overview of the current application status and future development of these technologies.

EBUS can scan tissue structure around the trachea and bronchus for ultrasonic images. EBUS is commonly used for localization of lesions, but its imaging diagnostic value has rarely been studied. RP-EBUS without water capsule can display the morphological characteristics in grayscale imaging, including shape, size, margin, echogenicity, and blood vessels of PPLs. CP-EBUS with water capsule device can also reflect the blood flow and relative stiffness of PPLs. The two ultrasound articles in this column constructed scoring models using RP-EBUS and CP-EBUS sonographic features, respectively, to assist bronchoscopists in distinguishing malignant from benign PPLs. In addition, transbronchial cryobiopsy has a higher diagnostic efficiency for PPLs but is associated with greater operation risk. Therefore, precise TBLC with guided bronchoscopy for lesion location is worthy of recommendation. The diagnostic value of VBN and RP-EBUS assisted TBLC for pulmonary lymphangitic carcinomatosis was also studied in this column.

I hope the readers will gain a more comprehensive understanding and get valuable inspiration on the use of guided bronchoscopy in PPLs.

\section{Acknowledgments}

Funding: None

\section{Footnote}

Provenance and Peer Review: This article was commissioned by the editorial office, Fournal of Thoracic Disease for the series "Advance in Bronchoscopy for Peripheral Pulmonary Diseases". The article did not undergo external peer review. 
Conflicts of Interest: The author has completed the ICMJE uniform disclosure form (available at http://dx.doi.org/10.21037/ jtd-2020-abpd-007). The series "Advance in Bronchoscopy for Peripheral Pulmonary Diseases" was commissioned by the editorial office without any funding or sponsorship. JS served as the unpaid Guest Editor of the series. The author has no other conflicts of interest to declare.

Ethical Statement: The author is accountable for all aspects of the work in ensuring that questions related to the accuracy or integrity of any part of the work are appropriately investigated and resolved.

Open Access Statement: This is an Open Access article distributed in accordance with the Creative Commons AttributionNonCommercial-NoDerivs 4.0 International License (CC BY-NC-ND 4.0), which permits the non-commercial replication and distribution of the article with the strict proviso that no changes or edits are made and the original work is properly cited (including links to both the formal publication through the relevant DOI and the license). See: https://creativecommons.org/licenses/by-nc$\mathrm{nd} / 4.0 /$.

\section{References}

1. Rivera MP, Mehta AC, Wahidi MM. Establishing the diagnosis of lung cancer: Diagnosis and management of lung cancer, 3rd ed: American College of Chest Physicians evidence-based clinical practice guidelines. Chest 2013;143:e142S-65S.

2. Schreiber G, McCrory DC. Performance characteristics of different modalities for diagnosis of suspected lung cancer: summary of published evidence. Chest 2003;123:115S-28S.

3. Dhillon SS, Harris K. Bronchoscopy for the diagnosis of peripheral lung lesions. J Thorac Dis 2017;9:S1047-58.

4. Wang Memoli JS, Nietert PJ, Silvestri GA. Meta-analysis of guided bronchoscopy for the evaluation of the pulmonary nodule. Chest 2012;142:385-93.

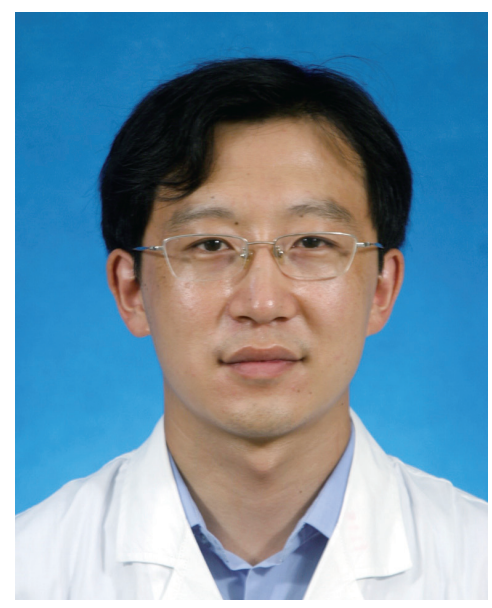

Jiayuan Sun 


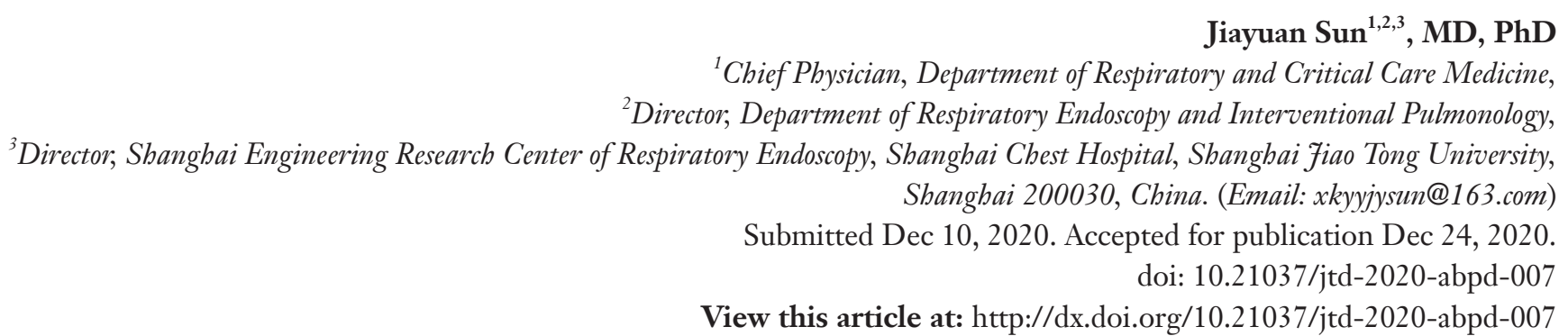

Cite this article as: Sun J. Introduction to fournal of Thoracic Disease new column of advance in bronchoscopy for peripheral pulmonary diseases. J Thorac Dis 2020;12(12):7642-7644. doi: 10.21037/jtd-2020-abpd-007 